\title{
DA IMORTALIDADE DOS MORTAIS NUM MUNDO SOMBRIO
}

\author{
DE LA IMORTALIDAD DE LOS MARTALES EN UM MONDO SOMBRIO
}

\author{
ON THE IMMORTALITY OF MORTALS IN A DARK WORLD
}

DE L'IMMORTALITÉ DES MORTELS DANS UN MONDE SOMBRE

DOI: 10.5533/1984-2503-20102508

Marildo Menegat

\section{RESUMO}

O autor discute a leitura de Hannah Arendt sobre a concepção de história de Karl Marx e o significado da sua aparentemente contraditória tese da abolição do trabalho ao mesmo tempo em que afirma esta atividade como central no processo de humanização. $O$ argumento demonstra que o trabalho é a forma dominante de sociabilidade da sociedade burguesa, mas não de outras formas sociais que venham a suprimi-la; e tampouco Marx foi alheio à possibilidade da realização dos indivíduos por meio de outras atividades que não o trabalho, como fica exposto, por exemplo, na sua concepção de "individualidade rica". Em favor de Arendt o autor argumenta que na experiência do séc. XX, a realização da lógica desta sociedade fez sobreporem-se os aspectos autodestrutivos do homem comum aos da criação da individualidade rica.

Palavras-chave: marxismo, história, trabalho, sociabilidade, tempo livre.

\section{RESUMEN}

El autor discute la lectura que Hannah Arendt realiza de la concepción de historia de Karl Marx y el significado de su tesis aparentemente contradictoria de la abolición del trabajo al mismo tiempo en que afirma esta actividad como central en el proceso de humanización. El argumento demuestra que el trabajo es la forma dominante de sociabilidad de la sociedad burguesa, pero no de otras formas sociales que la vayan a superar; y que Marx no fue ajeno a la posibilidad de realización de los individuos por medio de otras 
actividades diferentes del trabajo, como está expuesto, por ejemplo, en su concepción de "individualidad rica". A favor de Arendt, el autor argumenta que, en la experiencia del siglo $\mathrm{XX}$, la realización de la lógica de esta sociedad sobrepuso los aspectos autodestructivos del hombre común a aquellos de su creación de la individualidad rica.

Palabras-clave: marxismo, historia, trabajo, sociabilidad, tiempo libre.

\section{ABSTRACT}

The author discusses Hannah Arendt's interpretation of Karl Marx's understanding of history, and the meaning of his apparently contradictory thesis of abolition of labour, coupled with his notion that labour is central to the process of humanization. The argument shows that labour is the dominant form of socialization in bourgeois society, but not in other social formations that may overcome it. It cannot be said, either, that Marx was oblivious to the possibility of individual realization through activities other than labour, as witnessed by his concept of "rich individuality". Agreeing with Arendt, the author argues that in the experience of the 20th century, the logical realization of society caused humanity's destructive aspects to outdo those that might contribute to the creation of the rich individuality.

Key-words: Marxism, history, labour, sociability, free time.

\section{RÉSUMÉ}

L' auteur débat la lecture faite par Hannah Arendt sur la concéption d'histoire de Karl Marx et la signification de son thése, apparement contradictoire, de l'abolition du travail en même temps qu'il affirme cette activité comme centrale dans le processus d'humanisation. L'argument demontre que le travail est la forme dominante de la sociabilité dans la société bourgeoise, mais pas dans d'autres formes sociales que viennent a la surpasser. En plus, Marx n'a point ignoré la possibilité de la réalisation des individus par le moyen d'autres activités différentes du travail, comme on voit, par exemple, dans sa concéption de «l'individualité riche ». En faveur d'Arendt, l'auteur argumente que dans l'expérience du vingtième siècle, la réalisation logique de cette société a surposé les aspects destructifs de l'homme commun a ceux de la création de l'individualité riche.

Mot-clefs: marxisme, histoire, travail, sociabilité, temps libre.

O inicio do século XXI parece desde já marcado pelos impasses que dilaceram o 
mundo do trabalho. Poderíamos indicar este emaranhado de virada de época a partir de três perguntas: 1) $O$ trabalho estaria de fato com seus dias contados? 2) Estariam esgotadas as utopias produzidas neste universo, que marcaram tão profundamente os séculos XIX e XX? 3) É possível se produzir outra forma de sociabilidade que passe por fora do universo do trabalho?

Não será dada uma resposta imediata, negativa ou positiva, a cada uma dessas questões, mesmo porque tal simplismo pode ser desnorteador neste contexto. Nem mesmo se responderá de modo objetivo. Tentar-se-á, antes, conjugar uma série de reflexões, de diferentes autores, sobre alguns aspectos pertinentes a esses temas, de modo a encontrar um fio condutor que não apenas esclareça os impasses, mas que possa também apontar para uma crítica da felicidade medíocre com que as ciências humanas têm-se adequado às sociedades contemporâneas.

\section{I}

$\mathrm{Na}$ Ideologia Alemã, Marx e Engels discutem a interessante tese da superação (Aufhebung) do trabalho. Os autores estão ocupados em expor a nova concepção de história e suas consequências, em oposição aos ex-companheiros de viagem, os jovens hegelianos de esquerda. Dizem eles naquela obra: "a revolução comunista se dirige contra o modo da atividade até os nossos dias, elimina o trabalho e suprime o domínio de

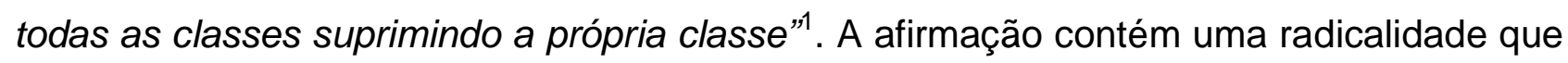
serve de eixo do projeto de uma nova forma social. Ela se produz, na verdade, na tensão da superação do trabalho através do próprio mundo do trabalho.

É possível que Marx e Engels tivessem em mente as Lições sobre a Filosofia da História de Hegel $^{2}$, da qual existem diversos traços na Ideologia Alemã, neste particular, a ideia da realização do espírito absoluto como fim da história. Para Hegel, esta forma do espírito se identificava com o advento dos tempos modernos que tinham na ética protestante a sua síntese mais acabada. Tanto Marx e Engels - que assinalam em notas de obras centrais, como em diversas passagens de outras menores - como mais tarde Weber - que fará desta questão uma tese sobre o espírito do capitalismo - associam a ética protestante com a ética do trabalho da sociedade burguesa. É neste quadro de referências que a citada passagem adquire seu significado e contornos polêmicos.

\footnotetext{
${ }^{1}$ Marx, Karl e Engels, Friedrich (1982). "A Ideologia Alemã". In: Obras Escolhidas; tomo I, Lisboa: Edições Avante, p. 31.

2 Hegel, Georg W. F. (1985). Lecciones sobre la filosofia de la história universal, Madri: Alianza Editorial.
} 
Contudo, os meios para a superação do trabalho não se reduzem aos aspectos intersubjetivos que são essenciais para tal revolução. Nos Grundrisse, Marx desenvolve esta questão como parte do telos do próprio desenvolvimento do capital. Neste caso, a superação do trabalho não seria um direito à preguiça na forma de uma utopia romântica regressiva do tipo "imitação do mundo tribal", mas sim um dado objetivo do desenvolvimento técnico da sociedade moderna. É esta premissa que torna legítima a afirmação da superação do trabalho. Marx diz nesta obra que a produção automatiza-se com a tendência ao crescimento do capital fixo, de tal maneira que a natureza fica submetida ao "conhecimento social geral - o general intellect".

O trabalho abstrato torna-se uma realidade predominante e, objetivamente, as mercadorias perdem seu espírito metafísico para assumirem, enfim, a forma de um produto concreto das forças produtivas gerais. $\mathrm{O}$ agir instrumental, que é a forma de ser da ação pertinente ao trabalho na sociedade capitalista, é absorvido pelo general intellect, e a atividade humana pode então se resumir a uma supervisão, "ao lado do processo de produção, ao invés de ser seu agente principal’3.

A nova expressão da riqueza se dará, segundo Marx, pela apropriação deste seu produto geral, que se revela na forma de tempo livre para o desenvolvimento pleno da individualidade rica. Este seria, em rápidas linhas, o caminho pensado por Marx e Engels no que se refere à superação do trabalho. Como vimos, ele se dá na intersecção do desenvolvimento da sociedade burguesa e da sua superação radical, produzindo com isso um novo topos social.

\section{II}

Hannah Arendt, no seu Between past and future ${ }^{4}$, elabora uma crítica ao que considera paradoxos presentes nesta tese de Marx e Engels. Na visão da autora, as insuficiências da tese residem nas contradições entre meios e fins. Com base nisso, ela procura formular um pensamento que realize um balanço crítico da crise da tradição a partir dos acontecimentos do século XX, marcados pela irrupção do totalitarismo. A sua perspectiva consiste em medir a tradição (na qual Hegel se inclui) e sua crítica (Marx e Engels) com estes novos fenômenos - sendo que o objetivo é compreender a natureza da sociedade que deles emerge. Para Arendt, nenhuma teoria pode ser responsável pelo

\footnotetext{
${ }^{3}$ Marx, Karl (1973). Elementos fundamentales para la crítica de la economia politica (borrador); vol. 2, Buenos Aires: Siglo XXI, p. 593.

${ }^{4}$ Faremos referência à edição francesa; Arendt, Hannah (1972). La Crise de la Culture, Paris: Éditions Gallimard.
} 
advir: o pensamento não é onipotente, no máximo é um sinal. Ao mesmo tempo, ele não é impotente, pode no mínimo aprender com o outro - no caso, as experiências traumáticas da modernidade e o que as engendrou.

Este posicionamento de certo modo relativista não é um princípio absoluto, mas a compreensão da condição humana e seus limites em determinados contextos sombrios. Pode parecer curioso que Arendt, ao invés de pensar a potencialidade positiva deste tempo - expressa, por exemplo, em concepções como a de individualidade rica de Marx se preocupe mais com o potencial destrutivo do homem comum. Mas há neste posicionamento uma dialética que se sustenta na impossibilidade da realização da individualidade rica, uma vez que esta estaria bloqueada por um domínio econômico, político e cultural que exige o tipo de homem comum do século XX, e este, por seu turno, é talhado à medida para exigir esse tipo de domínio. $O$ totalitarismo seria um fenômeno que surge de tal condição.

Estariam em jogo neste curto-circuito as formas de adesão da própria crítica ao que marcou o coração das trevas do século XX - para a autora, a experiência soviética estaria no mesmo campo de fenômenos que o nazismo e o fascismo. Num raciocínio centrípeto, as saídas à crise da tradição levariam ao mesmo lugar comum desta, numa vertigem em que tudo se enterra um pouco mais na lama e sempre. Num outro registro, o posicionamento de Arendt permite também vislumbrar o que se rompeu com estas experiências, avaliando a insuficiência das formulações da tradição que inspira a modernidade.

Contra Marx, Arendt insiste no paradoxo de sua tese acerca da centralidade do mundo do trabalho como um caminho da superação do reino das necessidades. Esta tese seria originária de uma determinada reflexão sobre a famosa dialética do senhor e do escravo de Hegel, e legitimaria a afirmação positiva da violência no vir-a-ser da história. Nisto consistiria a análise da condição do trabalhador moderno e de sua libertação - cujos meios passam, como dizia Marx, pela "maiêutica da história". O corolário desta tese seria a superação da filosofia, preconizada por Marx ainda em seus textos de juventude, que se tornaria possível com a abolição do domínio e exploração vigente no capitalismo.

Desta forma, proposição e corolário apontam para um mundo em que, uma vez surgido do uso consciente da violência e do fim da atividade contemplativa (a filosofia, por exemplo), restaria ao homem livre apenas o usufruto da abundância de bens. Arendt se pergunta: "se o trabalho é a mais humana e a mais produtiva das atividades dos homens, 
o que acontecerá, depois da revolução, se o trabalho será abolido?"5 Ou, após a revolução e o advento da sociedade sem classes, "nenhuma violência será mais possível?’6 A sua insistência nesta contradição se fundamenta no papel que, na tradição grega, desempenhavam a palavra, o debate, e a vida contemplativa, elementos constitutivos da atividade política, como formas de uma sociabilidade reflexiva dos cidadãos livres. Tais colocações dirigem-se contra o conceito de história de Marx e Engels.

\section{III}

Para Arendt, o conceito de história do mundo antigo fundava-se em duas qualidades imprescindíveis como eixos condutores da narrativa: a imparcialidade (cf. Homero, que dizia contar os feitos de Heitor e Aquiles sem julgar) e a objetividade (cf. Tucídides, que dizia serem os grandes atos e os grandes discursos evidentes por si mesmos). Parte dessa condição era determinada pela concepção de physis dos gregos, como uma natureza que compreende o homem, e à qual ele está indissoluvelmente ligado tanto pelo sentir, quanto por esta lhe servir de modelo para a existência. A physis como um percurso cíclico, isto é, imortal no seu eterno retorno e refazer, inscreve nascimento, maturidade e morte no mundo natural como reprodução do sempre-o-mesmo. Eram os homens que morriam, enquanto a memória material da natureza era percebida como eterno presente, por isso mesmo, como perene reprodução. Conforme perguntava Bob Dylan numa de suas canções, os anos de uma montanha e de uma pedra não importam. O que importa é a efemeridade da vida humana em sua produção social que, mesmo repetindo os ciclos da natureza nas dinâmicas de herança e reprodução das formas, não se constitui com a mesma força e grandeza. A elaboração desta efemeridade, contudo, é essencial para compreender o sentido da vida, o qual se constitui a partir de uma fragilidade difícil de ser sustentada.

A história como lembrança dos grandes homens em seus atos e palavras é um tipo especial de permanência, que se inscreve na aproximação destes homens à perenidade da natureza. Se a natureza é imortal nos seus ciclos, apenas a memória dos grandes atos e discursos pode transformar seus autores mortais em imortais. (Cabe registrar, e depois retornaremos a isso, que tal formulação soa estranha para o mundo cristão, uma vez que a imortalidade é uma das qualidades comuns a todas as almas, determinada por sua

\footnotetext{
${ }^{5}$ Arendt, Hannah (1972). Op. Cit., p. 36.

${ }^{6}$ lbidem, p. 37.
} 
gênese divina. Ou seja, o espírito, origem e destino do ser é que são eternos).

O herói nas epopeias não era um deus criador da natureza, mas um mortal que podia se igualar à perenidade desta. Seu segredo está no modo como vive a fragilidade humana, posta entre um mundo social que depende do esforço diário de cada um e de todos para se reproduzir e a força da natureza, que segue seu destino imortal como realização de sua própria matéria.

Para os gregos, este segredo residia na psique (a alma), consistindo no que distingue o homem em meio à força da physis. A psique é o elo do homem que mantém vivas tanto a sua diferença como a participação na physis. E a presença dela enquanto lembrança é o que permanece após a morte de um grande homem, fazendo que as reminiscências de sua existência dependam apenas de alguém evocá-las para que ele continue participando e atuando entre os vivos. A filosofia clássica antiga concedeu a este tema um lugar de honra. A sua força em dar um sentido à fragilidade da condição humana explicava a potencialidade do homem de se reconciliar com a natureza. Reconciliação que dependeria do cultivo do espírito enquanto desenvolvimento das formas que o elevam ao mundo imortal.

Tal concepção, como assinalado, não parte da imortalidade da alma, como ocorre no cristianismo. O registro da existência de alguém após a morte, a sua presença ativa entre os vivos nos grandes debates da polis, posto que o corpo que a sustentava pereceu como parte dos ciclos da natureza, depende de sua capacidade de servir ainda de modelo, e nisto reside a objetividade da reconciliação. As qualidades humanas - que são construídas socialmente enquanto virtudes que refletem esta condição de existência - se colocam como potência de um mundo intersubjetivo, e não como um imperativo. (Portanto, estão mais próximas à idéia de eticidade de Hegel do que à de moralidade de Kant).

Neste contexto, segundo Arendt ${ }^{7}$, a objetividade era evidente, uma vez que partia de uma crença comum nas virtudes e nos modelos compartilhados que a realizavam, e a imparcialidade era sua decorrência, já que não se trata do reconhecimento de um interesse particular, ou seja, de uma reminiscência limitada à esfera da vida privada, mas de um posicionamento público, logo, político.

A grande ruptura com tal concepção, ruptura esta que é a marca distintiva dos tempos modernos e de seu ethos, foi realizada pela concepção judaico-cristã da vida e da imortalidade da alma. No cristianismo, a vida natural é a mais mortal das existências. $\mathrm{O}$ ${ }^{7}$ Ibidem, p. 58-71. 
eterno retorno do mesmo significa um eterno refazer-se de outro. O corpo é perecível e a matéria de que é composta a natureza, perigosamente frágil e efêmera. A psique não seria o que nos leva à reconciliação com a physis, mas o que nos separa dela. Seria a memória intemporal da existência de cada um, que nos reconcilia com o espírito, como força do deus criador inscrita em cada um de nós.

O mundo judaico-cristão, quando comparado ao greco-romano, poderia ser entendido como um corte epistemológico que prepara o mundo burguês. A separação entre physis e psique, com a concepção de criação do mundo natural e do homem por um ser uno e único, transformam significativamente o sentido da objetividade e da imparcialidade. A coisa externa já não é um mundo contemplável no qual o homem estaria incluído como um elo fraco, mas o espaço de domínio daqueles que são a imagem e a semelhança do criador. A objetividade, agora, somente é possível como produto do acordo dos interesses particulares. Desse modo, ela não é mais evidente, porque depende do confronto de subjetividades (juízos) diferentes.

Se, para o grego, a opinião (a doxa) era a participação no mundo da polis como parte da objetividade da physis, para o moderno a opinião (o juízo) é a participação do interesse privado na vida pública, como um contrato feito a partir do - e para o - domínio da natureza que, como visto, já não guarda nada do conceito da velha physis. Na ilusão moderna, o domínio da natureza é um ato individual (as robinsonadas a que Marx se referia na Crítica da Economia Política), e a sociedade tem apenas o papel de proteger o homem contra o próprio homem. O senso comum, então, adquire a manifestação de uma subjetividade e de uma modalidade do sentir como algo anterior e mais seguro do que a inatingível realidade objetiva. ${ }^{8}$

\section{IV}

O conceito de "fazer história", recorrente na tradição moderna, teria começado, segundo Arendt, com o pensador napolitano do século XVII, Giambatista Vico. Este fazer, diz a autora, é da mesma natureza daquele em que é concebida a ciência moderna por Galileu e Descartes, assim como o trabalho. Aqui, história, conhecimento e ação produtiva se mesclariam numa única forma cultural.

Contudo, pode-se questionar esta afirmação de Arendt sobre Vico. Em princípio, porque ele foi um critico da concepção cartesiana da dedução e do abandono do mundo sensível como forma do conhecimento. Em segundo lugar, porque Vico viu a história ${ }^{8}$ Cf. Ibidem, p. 72-74. 
como processus, mas não como progresso linear, o que, entretanto, Arendt nos induz a desdobrar como uma consequência lógica daquele.

Para o autor italiano, a história dos povos é cíclica, sendo a decadência inerente a todos, a menos que se possa constituir uma "república das letras", ideia que em diversos aspectos também está presente no conceito de individualidade rica de Marx e que, como veremos, realizaria o campo possível das preocupações de Arendt. Por fim, porque Vico separa os universos da história e da ciência da natureza, justamente para reforçar a não aceitação do determinismo do destino dos povos e dos maus governantes ${ }^{9}$. Não por acaso, a obra de Vico volta a ser lida somente na época da Revolução Francesa, com historiadores como Jules Michelet. Vico pretende, com a separação de domínios, afirmar que o homem pode evitar a naturalização do mundo social, isto é, seu eterno decair.

É um equivoco pensar, como Arendt, que apenas o homem, em sua condição de existência desamparada, é imprevisível. Isto significaria uma concepção de natureza de fato eterna e, por conseguinte, um tanto quanto imutável e previsível, quando na verdade é justamente a irrupção do caráter inconsciente e imprevisível da sua dinâmica aquilo que Vico pretende pensar, para que sejam evitadas suas consequências na vida social.

Além disso, uma das características dos fenômenos sombrios do século $X X$ foi justamente a capacidade de destruição da natureza que seguidos e cerrados anos de industrialização produziram. Neste sentido, os argumentos de Arendt sobre este tema excedem em diversos aspectos a construção do objeto da sua crítica. O "fazer história" de Vico, que deu origem a uma longa tradição plebeia radical na modernidade, não possui a mesma natureza da mobilização das massas efetivada pelos regimes totalitários, como pretende nossa autora.

Em outras palavras, movimentos de massas não respondem em si pela mesma razão, apenas uma postura em certos termos conservadora pode considerar que qualquer ação coletiva seja sempre e tão somente destrutiva. Porém, num sentido diverso daquele suposto por ela, há de fato uma saturação do fazer e do fabricar nas formas da vida social burguesa que produzem um tipo de massas completamente manipulável.

\section{V}

A centralidade do conceito de fabricação na modernidade, com reflexos na concepção de história, segundo Arendt, teria transformado completamente a questão do “imortalizar os mortais", sugerido por Aristóteles em sua Metafísica como a mais elevada ${ }^{9}$ Croce, Benedetto (1962). La Filosofia di Giambatista Vico, Bari: Laterza. 
das atividades humanas, na qual se realizaria a vida contemplativa. Esse ponto de vista é rompido pelo método das ciências modernas, as quais fazem da manipulação e do domínio da natureza a sua intenção principal, se não exclusiva. A manipulação, ao exigir de todo conhecimento um princípio ativo como resultado, conduz a um problema de difícil solução acerca da objetividade e das formas constitutivas do real, ainda mais numa cultura talhada pelo fundamento do interesse como razão de todo fazer. Em resumo, a manipulação e o domínio estão para ciência como o interesse estaria para a vida prática. Se este princípio de verdade-objetiva da ciência produz um modelo que se ampliará como critério da verdade às ações humanas, ignorando as intenções, mas não os resultados, então uma conseqüência óbvia é a transformação do conceito de verdade em "mera funcionalidade", ou, o que dá no mesmo: em utilidade.

Todavia, não é o uso das coisas voltado à satisfação das necessidades comuns a todos a marca da racionalidade do interesse privado, mas o valor de troca. Assim, utilidade e verdade no mundo burguês se metamorfoseiam em simples validade, pobre registro da funcionalidade. Não importa que o mundo do trabalho seja movido por pessoas que fazem sem o saber e que, inclusive, a maioria sequer vá consumir o que produz. O que importa é que tais valores representam o domínio sobre a natureza e o progresso necessário à acumulação de capital.

Daqui deriva a validade das formas do real, sendo que a ética do trabalho, que é uma ética da ação tout court, funciona como um cimento subjetivo que sustenta este processo. A crítica de Marx ao mundo burguês está voltada justamente ao caráter alienado desta ação, que nunca se finaliza no consumo (o valor de uso). Ao não se finalizar, ao transformar a produção da vida social em produção pela produção, a criação universal de riqueza se torna uma verdadeira destruição universal, e, por isso, um processo social e histórico monstruoso, uma vez que desprovido de mediações reflexivas.

Então, se não há mais como "imortalizar os mortais" num mundo em que desapareceu a "velha alternativa entre uma vida individual imortal, num mundo mortal, e uma vida mortal, num mundo imortal"10, este dilema, para Arendt, acaba se resolvendo pela assunção da ação em si como o meio para dar um sentido à vida. Esta mediação, desprovida de finalidade (que seria seu momento reflexivo), que se transfere da ciência para a política, e da política para a história, tem suas raízes fundadas na vida prática ao se produzir na forma de acúmulo sem fim de riquezas. A reminiscência que imortaliza os mortais na sociedade burguesa é a sua contribuição e sucesso nesta dinâmica de moer ${ }^{10}$ Arendt, Hannah (1972). Op. Cit., p. 100. 
ossos humanos como um fim em si mesmo. Com ela adquire sentido a ideia de progresso ${ }^{11}$ que domina as sociedades modernas, e com ela se produz, sob a ilusão dos recursos infinitos da natureza, e sob o pesadelo real das possibilidades da fabricação de outra natureza (com sua absoluta humanização, sem a correspondente naturalização do homem, como preconizava o jovem Marx nos seus Manuscritos de 1844), o afastamento de qualquer possibilidade de liberdade e reconciliação. É este fenômeno, distinto daquele pensado por Arendt, que explica a manipulação das massas. Este princípio de fabricação eterna de valores - e não uma concepção de história que se pensa a partir do fazer desencadeia um estado de coisas cujas consequências regressivas são visíveis por toda parte.

Demonstra esse estado a crescente destruição necessária para que a acumulação de capital prossiga, com o emprego de técnicas que relegam o homem comum, numa sociedade cujo sentido da existência está posto na fabricação e no trabalho, a uma situação de absoluta falta de trabalho; assim como a crescente destruição da natureza e do próprio sentido do homem como um ser natural automediado. Tais problemas tendem a se tornar uma deformação sem retorno.

É neste mundo em que a possibilidade de tempo livre se mistura à impossibilidade da sua socialização - não apenas pela não realização do consumo dos bens produzidos que se manifesta a própria incapacidade dos homens associados se pensarem para além de uma vida de manipulação e domínio. Que a arte tenha sido reduzida a uma distração entretenimento -, isto é, a uma ação engajada na lógica da produção pela produção, na singular forma de uma produção improdutiva, é um sinal para se pensar a envergadura do estrago. Que esse estado, o qual seria admirado por todas as civilizações anteriores pelas condições de realização das mais elevadas e generosas aspirações da humanidade, se torne no seu oposto, pode apenas ser explicado pelas contradições dissolutivas que o movem.

\section{VI}

O percurso pelas idéias de Arendt teve um duplo sentido. Primeiro, o de indagar, através de críticas endereçadas a Marx e Engels, por que certo potencial emancipatório esperado por eles e presente neste tempo não se realizou. Em segundo lugar,

\footnotetext{
${ }^{11}$ Existem semelhanças surpreendentes entre estas formulações sobre história e progresso e as de Foucault, Michel (1966). Les Mots et les Choses, Paris: Éditions Gallimard. Confrontar em especial o prefácio e o capítulo $X$.
} 
demonstrar, através da própria exposição da autora, os limites de sua crítica. Os impasses do século XXI são a continuidade da história trágica do século $X X$. Este serve de modelo para aquele, principalmente nos seus momentos abertamente regressivos. Mais do que nunca a conjunção de imensas potencialidades libertárias com a impotência da ação intersubjetiva deve ser buscada nos fundamentos da estrutura social, e nas experiências que se seguiram nestes últimos 150 anos.

Nestes anos recentes, como um dos sintomas da crise, tem aparecido uma espécie de subliteratura de reformadores que, talvez na maior das boas intenções - desde que bem remuneradas! -, pregam o exercício do ócio criativo como uma solução ao dilema do desemprego estrutural. Autores como Domenico De Masi ${ }^{12}$, que circulam com desenvoltura entre os ambientes de executivos, vendem ilusões - embora nem sempre a preços de pechincha. Esperam dos ouvidos cansados do som rotineiro dos pregões das bolsas de valores que se sensibilizem com a obviedade do que os velhos comunistas da III Internacional costumavam chamar de condições objetivas maduras para a realização de outra forma social. A ilusão não provém do diagnóstico de tempo histórico, que até possui alguns traços de lucidez, na medida em que sinaliza uma situação histórica limite, mas de esperar que a falta da revolução seja suprida por aqueles que são a personificação dos impasses da humanidade. Se a aposta de Marx e Engels não se realizou, não será com o retorno ao mito das elites iluminadas que se superará o imbróglio.

A questão daí surgida, então, não é de fácil digestão em tão curto espaço, mas vale a pena ser esboçada. Seria a proposição de um movimento de leitura do velho Hegel, prestando mais atenção à forma do que ao conteúdo. Nas mesmas Lições sobre a Filosofia da História Universal, o autor defende a pouco sustentável tese de que na Alemanha não se fazia necessária uma revolução como a que ocorreu na França em 1789, pois, segundo seu argumento central, esta já havia ocorrido com a Reforma Protestante. Como já mencionado, tal marco inaugura o que Hegel concebeu como a nova eticidade dos tempos modernos.

Se o caminho de vendedores de ideias como De Masi, que pressupõe argumentos sensíveis para modificar a postura de altos executivos do mercado global, parece estar interditado pelo próprio "bom senso" da lógica capitalista, o caminho das revoluções ao estilo de 1789 e 1917, que tanto incendiaram a imaginação dos revolucionários, também parece estar interditado. Vistos à distância - e aqui a observação de Hegel ganha sentido

${ }^{12}$ De Masi, Domenico (1997). Sviluppo Senza Lavoro, Roma: Edizione Lavoro. 
-, pode-se dizer que tais movimentos nunca foram simples revoluções políticas realizadas num tempo concentrado, mas verdadeiras transformações das estruturas sociais que iniciaram muitos anos antes e que prosseguiram muitos anos depois.

A produção de uma sociabilidade que vá para além do mundo do trabalho e que não sucumba com este limite como se fosse o fim da história deve certamente ater-se a esses detalhes. O processo em andamento, de dissolução da forma social burguesa removida por contradições incontornáveis, que por enquanto tem ocorrido como uma aberta regressão à barbárie, pode também - e há sinais disso em práticas de movimentos sociais como o MST, no Brasil, e de alguns setores dos piqueteiros, na Argentina - criar novas dimensões de superação desta sociedade. Em meio a tais elementos podem surgir centelhas de outra forma social em que o tempo livre frustrado na forma de desemprego estrutural de hoje venha a ser o emergir de novas formas de atividades humanas produtivas, em que a rica individualidade, como Marx pensava, só não será possível se a humanidade trair seus melhores sonhos.

É bom não esquecer, porém, que na sociedade burguesa, em que os indivíduos estão submetidos a brutais relações sociais alienadas, não raramente se trocam sonhos por pesadelos como se se tratasse da escolha de uma sessão de cinema. E esta ilusão nada tem de logro, mas é parte da própria objetividade.

\section{Bibliografia}

Arendt, Hannah (1972). La Crise de la Culture, Paris: Éditions Gallimard.

Croce, Benedetto (1962). La Filosofia di Giambatista Vico, Bari: Laterza.

De Masi, Domenico (1997). Sviluppo Senza Lavoro, Roma: Edizione Lavoro.

Foucault, Michel (1966). Les Mots et les Choses, Paris: Éditions Gallimard.

Hegel, Georg W. F. (1985). Lecciones sobre la filosofia de la história universal, Madri: Alianza Editorial.

Marx, Karl e Engels, Friedrich (1982). "A Ideologia Alemã". In: Obras Escolhidas; tomo I, Lisboa: Edições Avante. 
Marx, Karl (1973). Elementos fundamentales para la crítica de la economia politica (borrador); vol. 2, Buenos Aires: Siglo XXI. 